\title{
Efeito da hipomagnesemia e da suplementação de magnésio sobre a insuficiência renal aguda pós-isquêmica*
}

\author{
Effect of hypomagnesemia and magnesium \\ supplementation on postischemic renal failure*
}

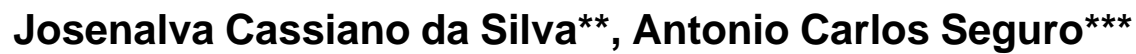

Silva, JC, Seguro AC. Efeito da hipomagnesemia e da suplementação de magnésio sobre a insuficiência renal aguda pós-isquêmica. Rev Med (São Paulo) 2002 jan./dez.;81(1/4):1-7.

RESUMO: Hipótese: Este trabalho visa avaliar os efeitos da hipomagnesemia e da suplementação de magnésio na insuficiência renal aguda pós- isquêmica. Materiais e Métodos: Foram utilizados ratos machos Wistar, divididos em cinco grupos: controle, hipomagnesêmico, isquêmico, hipoMg + isquêmico, suplementado + isq. Foi feito o estudo de clearance de inulina e a determinação de medidas funcionais. Resultados: A hipomagnesemia no contexto de uma isquemia renal levou a uma queda mais acentuada do RFG (Cin) e FSR e aumento da RVR. Nos animais suplementados, houve um aumento dos valores de $\mathrm{Cin}$ e $\mathrm{FeH}_{2} \mathrm{O}$. Conclusões: A hipomagnesemia na insuficiência renal aguda (IRA) potencializa os efeitos desta sobre a função renal. A suplementação de Magnésio protege parcialmente dos efeitos da IRA pós-isquêmica.

DESCRITORES: Ratos Wistar; Insuficiência renal aguda/fisiopatologia; Deficiência de magnésio/complicações; Suplementos dietéticos/efeitos adversos; Isquemia/complicações.

\section{INTRODUÇÃO}

O magnésio é o quarto cátion mais abundante no organismo e o segundo no meio intracelular, desempenhando um papel - chave em várias funções orgânicas. Na célula ele se encontra predominantemente ligado ao ATP, nucleotídeos e complexos enzimáticos, atuando em inúmeras funções celulares. Sistemicamente, participa da regulação da secreção de PTH (paratormônio), diminui a pressão sangüínea e altera a resistência vascular periférica ${ }^{17}$. Este último efeito, inclusive, faz com que o magnésio tenha um efeito protetor no pós-operatório de cirurgias cardíacas, pois minimiza a vasoconstrição induzida por agonistas, diminuindo o risco de desenvolvimento de arritmias cardíacas e queda do débito cardíaco nestes pacientes ${ }^{24}$.

De toda a reserva orgânica de magnésio, aproximadamente $60 \%$ encontra-se nos ossos e $40 \%$ nos tecidos moles, sendo que $99 \%$ desta carga é intracelular ${ }^{17}$. A concentração normal de magnésio no sangue é mantida dentro de estreitos limites e varia de 1,7 a $2,1 \mathrm{mg} / \mathrm{dL}^{17}$.

O principal regulador do magnésio no organismo é o rim, onde 3 a $5 \%$ da carga filtrada é excretada pela urina. Tal reabsorção tubular pode ser reduzida por diversos fatores como a expansão do volume extracelular, ingestão de álcool, dentre

* Prêmio Oswaldo Cruz (Área Básica) - XXI COMU Congresso Médico Universitário da FMUSP.

${ }^{* *}$ Acadêmica da FMUSP.

*** Prof. Dr. Livre-Docente da Disciplina de Nefrologia (orientador).

Endereço para correspondência: Rua Teodoro Sampaio, 281 quarto 11. Pinheiros, CEP: 05405-000 São Paulo-SP. 
outros $^{12}$. Diferentemente de outros íons, não há controle hormonal sobre a concentração plasmática de magnésio, a qual é a principal reguladora da reabsorção deste íon no néfron ${ }^{1}$.

Considera- se que há hipomagnesemia quando a concentração plasmática de magnésio é inferior a $1,5 \mathrm{mg} / \mathrm{dL}$. É um distúrbio comumente encontrado na prática clínica, atingindo cerca de $12 \%$ dos pacientes hospitalizados, podendo chegar a $65 \%$ naqueles sob cuidados intensivos ${ }^{1,2}$. Após um infarto agudo do miocárdio, por exemplo, é comum o paciente apresentar hipomagnesemia, o que o deixa mais vulnerável ao desenvolvimento de arritmias cardíacas, um novo evento isquêmico ou até mesmo morte súbita ${ }^{5,24}$. A diurese após obstrução pós-renal ou transplante renal também pode levar a grandes perdas de magnésio, deixando o paciente em estado de carência ${ }^{6,26}$.

Dentre as causas da hipomagnesemia é possível agrupá-las em cinco classes ${ }^{15}$ : causas nutricionais (por exemplo, alcoolismo ${ }^{12}$ ); causas intestinais (como a diarréia crônica e a má-absorção); causas endócrinas/metabólicas (como o hipertireoidismo); causas renais (uso do cisplatina ${ }^{3}$ ) e condições associadas ao período neo-natal e infância. Seus sinais e sintomas freqüentemente estão associados ou mascarados pelas manifestações da doença de base ou distúrbios associados ${ }^{12}$. Entretanto alguns são bem sugestivos da carência de magnésio como a hipopotassemia, hipocalcemia, sinais de Chvostek e Trousseau positivos e fraqueza generalizada ${ }^{1,17}$.

Em pacientes com doença coronariana, sabese que o magnésio exerce um papel importante na melhora da função endotelial ${ }^{14}$, na supressão do espasmo coronário naqueles que apresentam angina ${ }^{13}$ e parece minimizar a trombose dependente de plaquetas ${ }^{7}$.

Estudos baseados em isquemia, apontam para um possível efeito protetor do magnésio na perda auditiva ${ }^{19}$, na preservação da função hepática ${ }^{20}$ e na perda neuronal ${ }^{16}$. Entretanto, pouco se sabe sobre 0 papel deste íon no contexto da isquemia renal, bem como de suas repercussões.

\section{OBJETIVOS}

Avaliar o efeito isolado da hipomagnesemia induzida por dieta sem magnésio sobre o rim de uma animal não submetido à isquemia.

Avaliar os efeitos da depleção de magnésio sobre o rim de ratos submetidos à isquemia bilateral de 30 minutos por meio da análise de um grupo controle e de outro com dieta deficiente em magnésio.

Avaliar o efeito da suplementação de magnésio sobre a isquemia renal. A suplementação foi feita na água, utilizando- se $\mathrm{MgCl}$. $6 \mathrm{H}_{2} \mathrm{O}$ a $1 \%$.

\section{MATERIAIS E MÉTODOS}

Foram utilizados ratos machos Wistar, pesando entre 200 a 260 gramas, fornecidos pelo Biotério Central da Faculdade de Medicina da Universidade de São Paulo.

Os animais foram mantidos em dieta normal ou sem magnésio por 21 dias, de acordo com o grupo a que pertenceram.

\section{Estudo de clearance}

Neste experimento de clearance, os animais são anestesiados com pentobarbital $(50 \mathrm{mg} / \mathrm{kg}$ de peso), por via intra-peritoneal. A traqueostomia é feita utilizando-se catéter de polietileno (PE 240), e os ratos são mantidos em respiração espontânea. Utiliza-se manômetro de mercúrio para o registro da pressão arterial média, através da cateterização da artéria femoral esquerda, com catéter de polietileno (PE50), a partir de uma incisão inguinal. $O$ ritmo de filtração glomerular (RFG) é medido pelo clearance de inulina (Cin). A inulina é injetada em uma dose inicial de $100 \mathrm{ml} / \mathrm{kg}$ de peso, seguido de dose contínua de $0.27 \mathrm{mg} / \mathrm{min}$ por todo o experimento de clearance. As veias jugulares são dissecadas e nelas introduzidos catéteres de polietileno (PE60), para a administração de inulina e solução salina. Através de uma pequena incisão abdominal, a bexiga urinária é dissecada e nela é introduzido catéter (PE240), para a coleta das amostras de urina. Após a preparação cirúrgica do animal, e da injeção de inulina, aguarda-se um período de 30 minutos para se iniciarem as coletas de urina (três coletas, em períodos de 30 minutos) e sangue (duas coletas, no início e no final do experimento) $O$ fluxo sangüíneo renal (FSR) é medido no final do experimento, com um sensor de fluxo ultra-sônico perivascular (T-106, Transonic System Inc. Ithaca, NY, USA), com seu probe colocado na artéria renal esquerda.

\section{Modelo de isquemia renal}

Após 21 dias em dieta normal, ou em dieta sem magnésio, os animais foram anestesiados com pentobarbital, e foi feita laparotomia seguida de ligadura de artéria renal, bilateralmente. Após 30 minutos as ligaduras das artérias renais foram desfeitas, seguindose o fechamento da cavidade peritoneal. Os animais se recuperaram em gaiola metabólica. Os estudos de clearance foram feitos 48 horas após a isquemia.

\section{Grupos de estudo}

Grupo controle: animais mantidos em dieta normal, após 23 dias são submetidos ao estudo de clearance para posteriormente serem feitas as medidas funcionais. 
Grupo de hipomagnesemia: animais mantidos em dieta sem magnésio por 23 dias. Após este período foram submetidos ao estudo de clearance e medidas funcionais.

Grupo isquêmico: animais mantidos em dieta normal, após 21 dias são submetidos à isquemia para 2 dias após serem feitas as medidas funcionais.

Grupo de hipomagnesemia e isquêmico: animais mantidos em dieta sem magnésio por 21 dias. Após este período foram submetidos à isquemia e estudados dois dias após a reperfusão.

Grupo suplementado e isquêmico: animais mantidos em dieta sem Magnésio e com suplementação feita na água $\left(\mathrm{MgCl}_{2} 6 \mathrm{H}_{2} \mathrm{O}\right.$ a $\left.1 \%\right)$ por 21 dias. Após este período, foram submetidos à isquemia renal e dois dias após submetidos às medidas funcionais.

Determinações bioquímicas:

- a inulina foi determinada pelo método Antrona;

- os íons (sódio e potássio) plasmáticos e urinários foram medidos pelo espectrofotômetro de chama (modelo 143 da Instrumentation Laboratory Inc.);

- os valores dos três períodos de clearance foram a média de cada rato;

- o Magnésio e o Cálcio foram dosados no plasma de todos os grupos pelo Sistema Magnésio ou Cálcio Labtest, respectivamente.

\section{Parâmetros calculados}

1) Clearance de inulina (Cin) pela equação:

Cin = Uin.V/ Pin; onde

Uin é a concentração urinária de inulina em miligramas $\%$; Pin é a concentração plasmática de inulina em miligramas \%; V é o volume urinário em mililitros/minuto

2) Clearance de inulina corrigido pelo peso: $\mathrm{Cin} / 100 \mathrm{~g}=\mathrm{Cin} /$ peso $\times 100$

O peso considerado é o que foi medido no dia do clearance;

3) Fração de excreção de água: $\mathrm{FE} \mathrm{H}_{2} \mathrm{O}=\frac{\mathrm{V}}{\mathrm{C} i n} \times 100(\%)$ onde:

$\checkmark$ é o volume urinário em mililitros/minuto Cin é o clearance de inulina em $\mathrm{mL} / \mathrm{min}$
4) Fração de excreção de sódio e potássio: $\mathrm{FE}=\frac{\mathrm{U} . \mathrm{V} \cdot 100}{\operatorname{Cin} . \mathrm{P}}(\%)$ onde:

U.V é a excreção absoluta do eletrólito

Cin é o clearance de inulina

$\mathrm{P}$ é a concentração plasmática do eletrólito.

5) Cálcio e Magnésio plasmáticos:

Foram medidos pelo método Labtest.

6) Resistência vascular renal:

$\mathrm{RVR}=\mathrm{PA} / \mathrm{FSR}$, onde:

PA: é a pressão arterial do rato medida no dia do clearance;

FSR: é o fluxo sangüíneo renal.

\section{Análise estatística}

Para a análise dos cinco grupos estudados foi utilizado ANOVA com teste de Student - NewmanKeuls para a comparação das colunas entre si. Valores de $p<0,05$ foram considerados significantes.

\section{RESULTADOS}

A depleção de magnésio por 23 dias com queda dos níveis séricos deste cátion não alterou a função renal. De acordo com a Tabela 1 , as medidas funcionais como clearance de inulina, clearance de inulina corrigido pelo peso, volume urinário, dentre outras, foram estatisticamente semelhantes nos grupos controle e hipomagnesêmico. De modo análogo, os valores de hematócrito, PA, FSR e RVR não diferiram significativamente nos dois grupos (Tabela 4).

Como esperado, o grupo hipomagnesêmico apresentou níveis séricos mais baixos de magnésio e do cálcio (Tabela 3).

De acordo com os resultados ilustrados nas Tabelas 1 e 4, observa-se que a hipomagnesemia no contexto de uma isquemia renal levou a uma queda mais acentuada do clearance de inulina, do fluxo sangüíneo renal, bem como aumento da resistência vascular renal. Desta forma, a hipomagnesemia potencializou os efeitos da insuficiência renal aguda (IRA) pós-isquêmica.

Tabela 1- Filtração glomerular (Cin), volume urinário (Vu) e ganho de peso dos animais estudados.

\begin{tabular}{l|l|c|c|c}
\hline & Cin $(\mathbf{m L} / \mathbf{m i n})$ & Cin/100g (mL/min/100g) & Vu (mL/min) & Ganho de peso (g) \\
\hline Controle $(\mathrm{n}=6)$ & $1,92 \pm 0,172$ & $0,77 \pm 0,042$ & $0,0160 \pm 0,0040$ & $98,33 \pm 11,30$ \\
Hipo Mg $(\mathrm{n}=7)$ & $1,96 \pm 0,116$ & $0,83 \pm 0,031$ & $0,0104 \pm 0,0024$ & $70,14 \pm 7,64$ \\
Isquêmico $(\mathrm{n}=8)$ & $0,95 \pm 0,091 \mathrm{a}$ & $0,38 \pm 0,035 \mathrm{a}$ & $0,0191 \pm 0,0041$ & $75,75 \pm 2,42$ \\
Hipo Mg + isq. $(\mathrm{n}=7)$ & $0,48 \pm 0,064 \mathrm{a}$ & $0,22 \pm 0,032 \mathrm{a}$ & $0,0077 \pm 0,0008$ & $56,43 \pm 3,62 \mathrm{~d}$ \\
Suplementado $(\mathrm{n}=6)$ & $1,45 \pm 0,170$ & $0,54 \pm 0,078 \mathrm{c}$ & $0,0105 \pm 0,0012$ & $84,33 \pm 10,29$ \\
\hline
\end{tabular}

$\mathbf{a}, p<0,01$ vs. todos os outros grupos; $\mathbf{b}, p<0,01$ isquêmico vs. suplementado; $\mathbf{c}, p<0,05$ isquêmico vs. suplementado; $\mathbf{d}, p<0,01$ HipoMg+isq. vs. controle. ANOVA. 
Tabela 2- Frações de excreção de água $\left(\mathrm{FeH}_{2} \mathrm{O}\right)$, sódio (FeNa) e potássio (FeK) dos animais estudados.

\begin{tabular}{l|l|l|l}
\hline & Fe $\mathrm{H} O$ & Fe Na & Fe K \\
\hline Controle $(n=6)$ & $0,74 \pm 0,12$ & $0,79 \pm 0,16$ & $13,0 \pm 3,0$ \\
Hipo $\mathrm{Mg}(\mathrm{n}=7)$ & $0,58 \pm 0,12$ & $0,68 \pm 0,18$ & $6,9 \pm 1,13 \mathrm{~d}$ \\
Isquêmico $(\mathrm{n}=8)$ & $1,90 \pm 0,32 \mathrm{a}$ & $1,60 \pm 0,14$ & $23,37 \pm 2,81$ \\
Hipo Mg + isq. $(\mathrm{n}=7)$ & $2,26 \pm 0,54$ & $1,9 \pm 0,72$ & $36,80 \pm 7,74 \mathrm{c}$ \\
Suplementado $(\mathrm{n}=6)$ & $0,77 \pm 0,11 \mathrm{~b}$ & $0,91 \pm 0,13$ & $14,53 \pm 2,52$ \\
\hline
\end{tabular}

a, $\mathrm{p}<0,05$ vs. controle, hipoMg, suplementado; $\mathbf{b}, \mathrm{p}<0,05$ vs. isquêmico, hipoMg+isq.; c, $p<0,05$ vs. todos os outros grupos; $\mathbf{d}, \mathbf{p}<0,05$ vs. controle. ANOVA.
Tabela 3 - Concentrações plasmáticas de magnésio $(\mathrm{Mg})$ e cálcio $(\mathrm{Ca})$ dos animais estudados.

\begin{tabular}{l|l|l}
\hline & $M g(\mathrm{mg} / \mathrm{dL})$ & Ca $(\mathrm{mg} / \mathrm{dL})$ \\
\hline Controle $(\mathrm{n}=6)$ & $1,79 \pm 0,07$ & $9,15 \pm 0,34$ \\
Hipo Mg $(\mathrm{n}=7)$ & $0,81 \pm 0,04$ & $7,27 \pm 0,40$ \\
Isquêmico $(\mathrm{n}=8)$ & $1,51 \pm 0,12$ & $6,2 \pm 0,3 \mathrm{~d}$ \\
Hipo Mg + isq. $(\mathrm{n}=7)$ & $0,37 \pm 0,06 \mathrm{a}$ & $3,7 \pm 0,6 \mathrm{c}$ \\
Suplementado $(\mathrm{n}=6)$ & $2,03 \pm 0,15 \mathrm{~b}$ & $8,48 \pm 0,42$ \\
\hline
\end{tabular}

a, $p<0,05$ vs. controle, isquêmico, suplementado; $\mathbf{b}, p<0,05$ vs. hipoMg; c, $p<0,001$ vs. todos os outros grupos; $d, p<0,01$ vs. controle e suplementado. ANOVA.

Tabela 4 - Hematócrito (Ht), pressão arterial média (PA), fluxo sangüíneo renal (FSR) e resistência vascular renal (RVR) dos animais estudados.

\begin{tabular}{l|l|l|l|c}
\hline & $\mathrm{Ht}(\%)$ & $\mathrm{PA}(\mathrm{mmHg})$ & $\mathrm{FSR}(\mathrm{mL} / \mathrm{min})$ & $\mathrm{RVR}(\mathrm{mmHg} / \mathrm{mL} / \mathrm{min})$ \\
\hline Controle $(\mathrm{n}=6)$ & $45,5 \pm 0,76$ & $119,2 \pm 4,5$ & $7,38 \pm 0,16$ & $16,17 \pm 0,87$ \\
Hipo Mg $(\mathrm{n}=7)$ & $45,3 \pm 3,07$ & $114,3 \pm 3,2$ & $7,30 \pm 0,13$ & $15,86 \pm 0,51$ \\
Isquêmico $(\mathrm{n}=8)$ & $47,0 \pm 1,68$ & $114,4 \pm 2,9$ & $5,9 \pm 0,21 \mathrm{~b}$ & $19,5 \pm 0,73$ \\
Hipo Mg + isq. $(\mathrm{n}=7)$ & $44,0 \pm 2,22$ & $116,4 \pm 2,6$ & $2,7 \pm 0,39 \mathrm{a}$ & $49,71 \pm 7,80 \mathrm{a}$ \\
Suplementado $(\mathrm{n}=6)$ & $48,2 \pm 2,20$ & $110,3 \pm 1,3$ & $5,8 \pm 0,56 \mathrm{~b}$ & $19,97 \pm 1,98$ \\
\hline
\end{tabular}

a, $p<0,001$ vs. todos os outros grupos; $\mathbf{b}, \mathrm{p}<0,01$ vs. controle e hipoMg. ANOVA.

Com relação aos animais submetidos a uma dieta rica em magnésio, estes apresentaram um maior clearance de inulina quando comparados aos ratos submetidos à isquemia e em dieta normal, além de uma menor fração de excreção de água (Tabelas 1 e 2). Estes dados indicam que a suplementação de magnésio protegeu parcialmente os animais da insuficiência renal aguda pósisquêmica. Não se observaram diferenças quanto a hemodinâmica renal entre estes dois grupos de animais (Tabela 4).

O Gráfico 1 mostra os valores de ritmo de filtração glomerular obtidos em todos os grupos.

Em relação às frações de excreção de água e potássio estas diferiram significativamente entre os grupos. A fração de excreção de sódio, porém, não se alterou estatisticamente conforme mostra a Tabela 2.

As concentrações plasmáticas de Magnésio e Cálcio foram significativamente menores nos grupos isquêmicos se comparados aos grupos que não foram submetidos à isquemia. Quando se observa também o grupo suplementado, nota-se um aumento nos níveis destes íons.
Clearance de inulina $/ 100 \mathrm{~g}$ de peso $\mathrm{p}<0,0001$

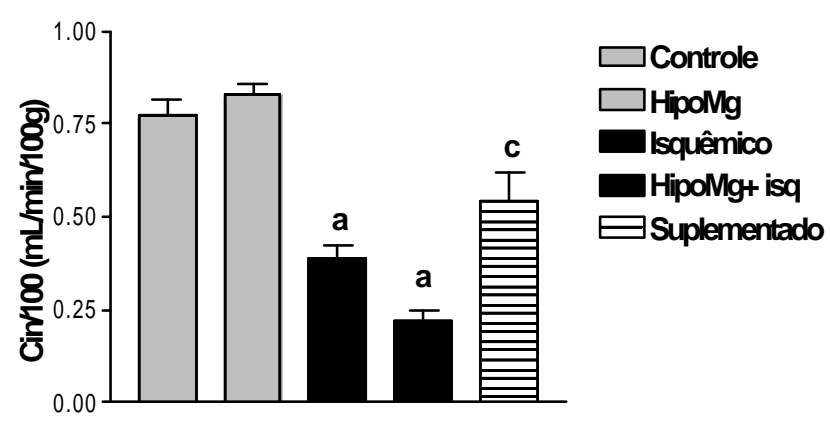

a: $p<0,01$ vs. todos os grupos

c: $\mathrm{p}<0,05$ isquêmico vs. suplementado

Grafico 1 - Valores de ritmo de filtração glomerular obtidos em todos os grupos.

Os Gráficos 2 e 3 mostram as concentrações plasmáticas destes íons vistas em todos os grupos.

A Tabela 4 mostra os valores de hematócrito, pressão arterial, fluxo sangüíneo renal e resistência vascular renal encontrados nos diferentes grupos. 


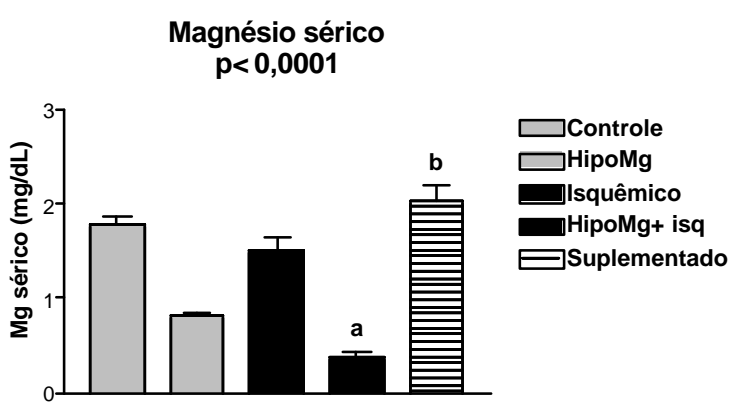

Gráfico 2 - Concentração plasmática de magnésio; a, $p<0,05$ vs controle, isquêmico e suplementado; $b$, $\mathrm{p}<0,05$ vs hipoMg.

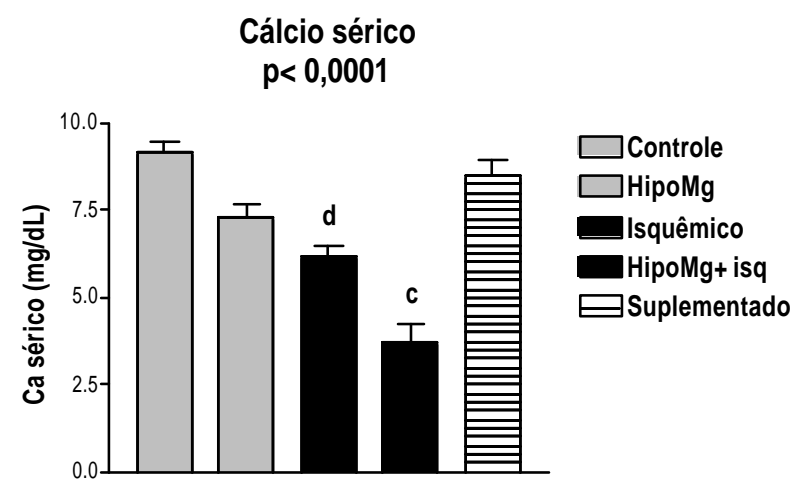

Gráfico 3 - Concentração plasmática de Cálcio c; $p<0,001$ vs. todos os outros grupos $d ; p<0,01$ vs. controle e suplementado.

\section{DISCUSSÃO}

A quantidade de magnésio na dieta é crítica na determinação dos níveis séricos de magnésio. Neste trabalho mostramos que a ausência de sais de magnésio na dieta por 21 dias foi suficiente para que os animais desenvolvessem um grau severo de hipomagnesemia. A desnutrição é muito freqüente em pacientes internados em Unidade de Terapia Intensiva e vários trabalhos observaram deficiência de magnésio muscular e sérico nestes pacientes principalmente nos portadores da síndrome da imunodeficiência adquirida ${ }^{10,18,25}$, indicando que este nosso modelo tem aplicação clínica óbvia.

O clearance de inulina medido 48 horas após isquemia renal nos animais mantidos em dieta normal foi de $0,38 \pm 0,04 \mathrm{ml} / \mathrm{min} / 100 \mathrm{~g}$; cerca da metade dos valores dos animais controles, demonstrando um comprometimento importante da filtração glomerular após este tempo de isquemia e reperfusão renal.

Nos animais com hipomagnesemia foi observado um valor médio de $0,20 \mathrm{ml} / \mathrm{min} / 100 \mathrm{~g}$, evidenciando que o distúrbio metabólico agravou a insuficiência renal.
Dentre os mecanismos possíveis, a vasoconstrição renal mais severa neste grupo de animais que levou à maior queda do fluxo sanguíneo renal nos mesmos ratos parece o mais provável. Em outros territórios como o miocárdio e o cérebro como vimos a hipomagnesemia produz vasoconstrição.

Já foi demonstrado que a hipomagnesemia inibe a liberação de óxido nítrico do endotélio das artérias coronárias ${ }^{24}$. O óxido nítrico como sabemos é um potente vasodilatador endógeno, desta forma, a hipomagnesemia poderia promover vasoconstrição renal via menor produção de óxido nítrico.

O magnésio é um bloqueador dos canais de cálcio $^{2}$. Na deficiência de magnésio ocorre um aumento do cálcio intracelular, o que também pode explicar a maior vasoconstrição e maior lesão celular no grupo de ratos com hipomagnesemia.

Outros mecanismos como aumento da produção de vasoconstritores como a endotelina e de citocinas pró-inflamatórias também já foram descritas neste distúrbio ${ }^{21}$ e provavelmente serão por nós explorados neste modelo com técnicas de imunohistoquímica.

O magnésio está envolvido no balanço iônico intracelular, tendo função importante sobre a atividade da Na-K-ATPase 4 . Na deficiência de magnésio ocorre uma redução dos níveis de ATP intracelular, menor função da Na-K-ATPase com aumento da concentração de sódio intracelular que pode levar à morte da célula. Este é um fator que poderia agravar - grau de necrose na lesão renal após isquemia e reperfusão do rim, como podemos constatar nos nossos experimentos através de maiores frações de excreção de água, sódio e potássio observadas no grupo de animais com hipomagnesemia.

Outro achado interessante neste trabalho foi o menor nível de cálcio plasmático total nos animais com hipomagnesemia. A hipocalcemia é comumente encontrada em associação com a hipomagnesemia. Embora a hipomagnesemia leve estimule a secreção de paratormônio, a hipomagnesemia severa suprime sua secreção assim como a hipermagnesemia, além do que o mecanismo de ação celular do paratormônio necessita de concentrações celulares normais de magnésio pois este cátion é necessário para a atividade da adenil-ciclase que é um transmissor do efeito intracelular do $\mathrm{PTH}^{22}$.

A hipocalcemia é muito freqüente em pacientes graves, principalmente naqueles com síndrome séptica. Existe uma correlação deste distúrbio com a severidade da doença, podendo colaborar com a alta letalidade da insuficiência renal aguda em pacientes desnutridos com hipomagnesemia ${ }^{11}$.

Estes resultados mostram claramente que a hipomagnesemia é um fator agravante da insuficiência 
renal aguda pós-isquêmica e nos motivam a estudar um novo grupo de animais submetidos ao mesmo protocolo de isquemia e reperfusão porém suplementados com cloreto de magnésio a $1 \%$ na água de beber que já utilizamos no Laboratório ${ }^{8}$.

Considerando que a ingestão média de água neste grupo foi de $30 \mathrm{ml}$ por dia, a quantidade ingerida de magnésio pelo rato (35 $\mathrm{mg}$ por dia) foi bem maior do que a existente em uma dieta normal em magnésio que contem $0,22 \mathrm{~g}$ de magnésio por quilo de dieta. Cada rato ingere em média 20 gramas de dieta por dia, portanto cerca de $4 \mathrm{mg} / \mathrm{dia}$.

Nossos resultados mostram claramente que os animais suplementados com magnésio apresentaram uma filtração glomerular significativamente maior que o grupo submetido à isquemia renal mantido em dieta normal.

A suplementação de magnésio tem sido mostrada como benéfica em modelos de insuficiência renal aguda nefrotóxica associados à vasoconstrição como a ciclosporina ${ }^{23}$, e mais recentemente com o indinavir em nosso laboratório ${ }^{8}$.

O fluxo sangüíneo renal não foi diferente quando comparados os animais suplementados ou não com magnésio e submetidos à isquemia. Este fato nos leva a crer que a suplementação de magnésio esteja agindo via aumento do coeficiente de permeabilidade glomerular (Kf). O magnésio pelo seu efeito bloqueador do canal de cálcio diminui a concentração de cálcio intracelular com conseqüente relaxamento das células musculares lisas. O magnésio inibe a contração produzida pela ciclosporina e angiotensina II nas células mesangiais em cultura9.

Este efeito protetor da suplementação de magnésio sobre a insuficiência renal aguda isquêmica será melhor estudado pelo nosso grupo com análise histológica de todos os grupos descritos e estudos de imunohistoquímica com a expressão de moléculas de adesão, PCNA e envolvimento de células como macrófagos e linfócitos.

\section{CONCLUSÃO}

A hipomagnesemia potencializa a insuficiência renal pós-isquêmica por levar a uma queda mais acentuada do clearance de inulina, fluxo sangüíneo renal, bem como aumento da resistência vascular renal. Já a suplementação de magnésio protege parcialmente os animais da insuficiência renal aguda pós isquêmica.

Silva, JC, Seguro AC. Effect of hypomagnesemia and magnesium supplementation on postischemic renal failure. Rev Med (São Paulo) 2002 jan./dez.;81(1/4):1-7.

ABSTRACT: Hypothesis:The aim of this study is to verify the effect of hypomagnesemia and magnesium supplementation on postischemic renal failure. Methods: Five groups of male Wistar rats were studied: control; posthypomagnesemic; post-ischemic; postischemic + hypomagnesemia and post-ischemic + magnesium supplementation. Clearance and hemodynamic measurements were performed.Results: In postischemic rats, hypomagnesemia induces a marked decrease in GFR, RBF and increases the RVR. In rats with Magnesium supplementation increased GFR and decreased $\mathrm{FeH}_{2} \mathrm{O}$ were observed when compared with rats on a normal diet.Conclusion: Hypomagnesemia potentiates postischemic renal failure and magnesium supplementation protects against renal ischemia.

KEYWORDS: Wistar, Rats; Kidney failure, acute/physiopathology; Magnesium deficiency/complication; Dietary supplemments/adverse effects; Ischemy/complications

\section{REFERÊNCIAS}

1. Ariceta G, Rodriguez-Soriano J, Vallo A, Navajas A. Acute and chronic effects of cisplatin therapy on renal magnesium homeostasis. Med Pediatr Oncol 1997;28(1):35-44.

2. Araujo M, Seguro AC. Magnesium supplementation attenuates indinavir nephrotoxicity. J Am Soc Nephrol 2001. [World Congress of Nephrology, 2001. Abstract. A4169].

3. Agus ZS. Hypomagnesemia. J Am Soc Nephrol 1999;10:1616-22.
4. Caddel J, Suskind R, Sillup H, Olsom RE. Parenteral magnesium load evaluation of malnourished Thai childen. J Pediatr 1973;83(1):129-35.

5. Chernow B, Bamberger S, Stoiko M, Vadnais M, Mill S, Hoellerich V, Warshaw AL. Hypomagnesemia in patients in the postoperative intensive care unit. Chest 1989;95(2):391-7.

6. Davis BB, Preuss HG, Murdaugh HV Jr. Hypomagnesemia following the diuresis of postrenal obstruction and renal transplant. Nephron 
1975;14(3-4):275-80.

7. Edmund B Flink. Magnesium deficiency. Etiology and clinical spectrum. Acta Med Scand Suppl 1981;647 (-HD-):125-37.

8. Flatman PW, Lew VL. The magnesium dependence of sodium pump mediated sodium- potassium and sodium- sodium exchange in intact human red cells. J Physiol 1981;315:421-46.

9. Frandey J, Rob PM, Jekelmann W. Theophylline and magnesium inhibit the contraction elicited with ciclosporine and angiotensin II in mesangial cell cultures. Nephron 1991;57(1):94-8.

10. Gupta BK, Glincklich D, Teilis VA. Magnesium repletion therapy improves lipid metabolism in hypomagnesemic transplant recipients: a pilot study. Transplantation 1999;67(11):1485-7.

11. Jeong C, Lee SM. The beneficial effect of ATP- $\mathrm{MgCl}_{2}$ on hepatic ischemia reperfusion-induced mitochondrial dysfunction. Eur J Pharmacol 2000; 403(3):243-50.

12. Johannesson AJ, Raisz LG. Effects of low medium magnesium concentration on bone resorption in response to parathyroid hormone and 1,25 dihydroxy vitamin D in organ culture. Endocrinology 1983; 113(6):2294-8.

13. Kelepouris E, Agus ZS. Hypomagnesemia: renal magnesium handling. Semin Nephrol 1998;18(1):58-73.

14. Liao F, Folsom AR, Brancati FL. Is low magnesium concentration a risk factor for coronary heart disease. The atherosclerosis risk in communities (ARIC) study. Am Heart J 1998;136(3):480-90.

15. Massry SG and Seelig MS. Hypomagnesemia and hypermagnesemia. Clin Nephrol 1977;7(4):14753.

16. Pearson PJ, Evora PR, Seccombe JF, Schaff HV. Hypomagnesemia inhibits nitric oxide release from coronary endothelium. Protective role of magnesium infusion after cardiac operations. Am Thorac Surg
1998;65(4):967-72.

17. Rao TK. Acute renal failure syndromes in human immunodeficiency virus infection. Semin Nephrol 1998;18(4):378-95.

18. Rob PM, Lebeau A, Nobiling R, Schimid H, Bley N, Dick K, et al. Magnesium metabolism: basic aspects and implications of ciclosporine toxicity in rats. Nephron 1996;72(1):59-66.

19. Sameshima H, Ikenoue T. Long- term magnesium sulfate treatment as protection against hypoxicischemic brain injury in seven-day-old-rats. Am J Obstet Gynecol 2001;184(2):185-90.

20. Shechter M, Merz CN, Rude RK, Paul Labrador MJ, Meisel SR, et al. Low intracellular magnesium levels promote platelet-dependent thrombosis in patients with coronary artery disease. Am Heart $\mathrm{J}$ 2000;140(2):212-8.

21. Shechter M, Shavir M, Labrador MJ, Forrester J, Silver $\mathrm{B}$, Bairey Merz CN. Oral magnesium therapy improves endothelial function in patients with coronary artery disease. Circulation 2000;102(19):2353-8.

22. Scheibe F, Haupt H, Vlastos GA. Preventive magnesium supplement reduces ischemia-induced hearing loss and blood viscosity in the guinea pig. Eur Arch Otorhinolaryngol 2000;257(7):355-61.

23. Teregawa $H$, Kato $M$, Yamagata $P$, Matsuura $H$, Kajiyama G. The preventive effect of magnesium on coronary spasm in patients with vasoespastic angina. Chest 2000;118(6):1690-5.

24.Zivin JR, Gooley T, Zager RA, Ryan MJ. Hypocalcemia: a pervasive metabolic abnormality in the critically ill. Am J Kidney Dis 2001;37(4):689-98.

25. Weglicki WB, Phillips TM, Freedman AM, Cassidy MM, Dickens BF. Magnesium deficiency elevates circulating levels of inflammatory cytokines and endothelin. Mol Cell Biochem 1992;110(2):169-73.

26. White RE, Hartzell HC. Effects of intracellular free magnesium on calcium current in isolated myocytes. Science 1988;239(4841 Pt 1):778-80. 


\title{
Efeito da hipomagnesemia e da suplementação de magnésio sobre a insuficiência renal aguda pós-isquêmica*
}

\author{
Effect of hypomagnesemia and magnesium \\ supplementation on postischemic renal failure*
}

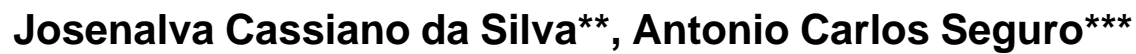

Silva, JC, Seguro AC. Efeito da hipomagnesemia e da suplementação de magnésio sobre a insuficiência renal aguda pós-isquêmica. Rev Med (São Paulo) 2002 jan./dez.;81(1/4):1-7.

RESUMO: Hipótese: Este trabalho visa avaliar os efeitos da hipomagnesemia e da suplementação de magnésio na insuficiência renal aguda pós- isquêmica. Materiais e Métodos: Foram utilizados ratos machos Wistar, divididos em cinco grupos: controle, hipomagnesêmico, isquêmico, hipoMg + isquêmico, suplementado + isq. Foi feito o estudo de clearance de inulina e a determinação de medidas funcionais. Resultados: A hipomagnesemia no contexto de uma isquemia renal levou a uma queda mais acentuada do RFG (Cin) e FSR e aumento da RVR. Nos animais suplementados, houve um aumento dos valores de $\mathrm{Cin}$ e $\mathrm{FeH}_{2} \mathrm{O}$. Conclusões: A hipomagnesemia na insuficiência renal aguda (IRA) potencializa os efeitos desta sobre a função renal. A suplementação de Magnésio protege parcialmente dos efeitos da IRA pós-isquêmica.

DESCRITORES: Ratos Wistar; Insuficiência renal aguda/fisiopatologia; Deficiência de magnésio/complicações; Suplementos dietéticos/efeitos adversos; Isquemia/complicações.

\section{INTRODUÇÃO}

O magnésio é o quarto cátion mais abundante no organismo e o segundo no meio intracelular, desempenhando um papel - chave em várias funções orgânicas. Na célula ele se encontra predominantemente ligado ao ATP, nucleotídeos e complexos enzimáticos, atuando em inúmeras funções celulares. Sistemicamente, participa da regulação da secreção de PTH (paratormônio), diminui a pressão sangüínea e altera a resistência vascular periférica ${ }^{17}$. Este último efeito, inclusive, faz com que o magnésio tenha um efeito protetor no pós-operatório de cirurgias cardíacas, pois minimiza a vasoconstrição induzida por agonistas, diminuindo o risco de desenvolvimento de arritmias cardíacas e queda do débito cardíaco nestes pacientes ${ }^{24}$.

De toda a reserva orgânica de magnésio, aproximadamente $60 \%$ encontra-se nos ossos e $40 \%$ nos tecidos moles, sendo que $99 \%$ desta carga é intracelular ${ }^{17}$. A concentração normal de magnésio no sangue é mantida dentro de estreitos limites e varia de 1,7 a $2,1 \mathrm{mg} / \mathrm{dL}^{17}$.

O principal regulador do magnésio no organismo é o rim, onde 3 a $5 \%$ da carga filtrada é excretada pela urina. Tal reabsorção tubular pode ser reduzida por diversos fatores como a expansão do volume extracelular, ingestão de álcool, dentre

* Prêmio Oswaldo Cruz (Área Básica) - XXI COMU Congresso Médico Universitário da FMUSP.

${ }^{* *}$ Acadêmica da FMUSP.

*** Prof. Dr. Livre-Docente da Disciplina de Nefrologia (orientador).

Endereço para correspondência: Rua Teodoro Sampaio, 281 quarto 11. Pinheiros, CEP: 05405-000 São Paulo-SP. 
outros $^{12}$. Diferentemente de outros íons, não há controle hormonal sobre a concentração plasmática de magnésio, a qual é a principal reguladora da reabsorção deste íon no néfron ${ }^{1}$.

Considera- se que há hipomagnesemia quando a concentração plasmática de magnésio é inferior a $1,5 \mathrm{mg} / \mathrm{dL}$. É um distúrbio comumente encontrado na prática clínica, atingindo cerca de $12 \%$ dos pacientes hospitalizados, podendo chegar a $65 \%$ naqueles sob cuidados intensivos ${ }^{1,2}$. Após um infarto agudo do miocárdio, por exemplo, é comum o paciente apresentar hipomagnesemia, o que o deixa mais vulnerável ao desenvolvimento de arritmias cardíacas, um novo evento isquêmico ou até mesmo morte súbita ${ }^{5,24}$. A diurese após obstrução pós-renal ou transplante renal também pode levar a grandes perdas de magnésio, deixando o paciente em estado de carência ${ }^{6,26}$.

Dentre as causas da hipomagnesemia é possível agrupá-las em cinco classes ${ }^{15}$ : causas nutricionais (por exemplo, alcoolismo ${ }^{12}$ ); causas intestinais (como a diarréia crônica e a má-absorção); causas endócrinas/metabólicas (como o hipertireoidismo); causas renais (uso do cisplatina ${ }^{3}$ ) e condições associadas ao período neo-natal e infância. Seus sinais e sintomas freqüentemente estão associados ou mascarados pelas manifestações da doença de base ou distúrbios associados ${ }^{12}$. Entretanto alguns são bem sugestivos da carência de magnésio como a hipopotassemia, hipocalcemia, sinais de Chvostek e Trousseau positivos e fraqueza generalizada ${ }^{1,17}$.

Em pacientes com doença coronariana, sabese que o magnésio exerce um papel importante na melhora da função endotelial ${ }^{14}$, na supressão do espasmo coronário naqueles que apresentam angina ${ }^{13}$ e parece minimizar a trombose dependente de plaquetas ${ }^{7}$.

Estudos baseados em isquemia, apontam para um possível efeito protetor do magnésio na perda auditiva ${ }^{19}$, na preservação da função hepática ${ }^{20}$ e na perda neuronal ${ }^{16}$. Entretanto, pouco se sabe sobre 0 papel deste íon no contexto da isquemia renal, bem como de suas repercussões.

\section{OBJETIVOS}

Avaliar o efeito isolado da hipomagnesemia induzida por dieta sem magnésio sobre o rim de uma animal não submetido à isquemia.

Avaliar os efeitos da depleção de magnésio sobre o rim de ratos submetidos à isquemia bilateral de 30 minutos por meio da análise de um grupo controle e de outro com dieta deficiente em magnésio.

Avaliar o efeito da suplementação de magnésio sobre a isquemia renal. A suplementação foi feita na água, utilizando- se $\mathrm{MgCl}$. $6 \mathrm{H}_{2} \mathrm{O}$ a $1 \%$.

\section{MATERIAIS E MÉTODOS}

Foram utilizados ratos machos Wistar, pesando entre 200 a 260 gramas, fornecidos pelo Biotério Central da Faculdade de Medicina da Universidade de São Paulo.

Os animais foram mantidos em dieta normal ou sem magnésio por 21 dias, de acordo com o grupo a que pertenceram.

\section{Estudo de clearance}

Neste experimento de clearance, os animais são anestesiados com pentobarbital $(50 \mathrm{mg} / \mathrm{kg}$ de peso), por via intra-peritoneal. A traqueostomia é feita utilizando-se catéter de polietileno (PE 240), e os ratos são mantidos em respiração espontânea. Utiliza-se manômetro de mercúrio para o registro da pressão arterial média, através da cateterização da artéria femoral esquerda, com catéter de polietileno (PE50), a partir de uma incisão inguinal. $O$ ritmo de filtração glomerular (RFG) é medido pelo clearance de inulina (Cin). A inulina é injetada em uma dose inicial de $100 \mathrm{ml} / \mathrm{kg}$ de peso, seguido de dose contínua de $0.27 \mathrm{mg} / \mathrm{min}$ por todo o experimento de clearance. As veias jugulares são dissecadas e nelas introduzidos catéteres de polietileno (PE60), para a administração de inulina e solução salina. Através de uma pequena incisão abdominal, a bexiga urinária é dissecada e nela é introduzido catéter (PE240), para a coleta das amostras de urina. Após a preparação cirúrgica do animal, e da injeção de inulina, aguarda-se um período de 30 minutos para se iniciarem as coletas de urina (três coletas, em períodos de 30 minutos) e sangue (duas coletas, no início e no final do experimento) $O$ fluxo sangüíneo renal (FSR) é medido no final do experimento, com um sensor de fluxo ultra-sônico perivascular (T-106, Transonic System Inc. Ithaca, NY, USA), com seu probe colocado na artéria renal esquerda.

\section{Modelo de isquemia renal}

Após 21 dias em dieta normal, ou em dieta sem magnésio, os animais foram anestesiados com pentobarbital, e foi feita laparotomia seguida de ligadura de artéria renal, bilateralmente. Após 30 minutos as ligaduras das artérias renais foram desfeitas, seguindose o fechamento da cavidade peritoneal. Os animais se recuperaram em gaiola metabólica. Os estudos de clearance foram feitos 48 horas após a isquemia.

\section{Grupos de estudo}

Grupo controle: animais mantidos em dieta normal, após 23 dias são submetidos ao estudo de clearance para posteriormente serem feitas as medidas funcionais. 
Grupo de hipomagnesemia: animais mantidos em dieta sem magnésio por 23 dias. Após este período foram submetidos ao estudo de clearance e medidas funcionais.

Grupo isquêmico: animais mantidos em dieta normal, após 21 dias são submetidos à isquemia para 2 dias após serem feitas as medidas funcionais.

Grupo de hipomagnesemia e isquêmico: animais mantidos em dieta sem magnésio por 21 dias. Após este período foram submetidos à isquemia e estudados dois dias após a reperfusão.

Grupo suplementado e isquêmico: animais mantidos em dieta sem Magnésio e com suplementação feita na água $\left(\mathrm{MgCl}_{2} 6 \mathrm{H}_{2} \mathrm{O}\right.$ a $\left.1 \%\right)$ por 21 dias. Após este período, foram submetidos à isquemia renal e dois dias após submetidos às medidas funcionais.

Determinações bioquímicas:

- a inulina foi determinada pelo método Antrona;

- os íons (sódio e potássio) plasmáticos e urinários foram medidos pelo espectrofotômetro de chama (modelo 143 da Instrumentation Laboratory Inc.);

- os valores dos três períodos de clearance foram a média de cada rato;

- o Magnésio e o Cálcio foram dosados no plasma de todos os grupos pelo Sistema Magnésio ou Cálcio Labtest, respectivamente.

\section{Parâmetros calculados}

1) Clearance de inulina (Cin) pela equação:

Cin = Uin.V/ Pin; onde

Uin é a concentração urinária de inulina em miligramas $\%$; Pin é a concentração plasmática de inulina em miligramas \%; V é o volume urinário em mililitros/minuto

2) Clearance de inulina corrigido pelo peso: $\mathrm{Cin} / 100 \mathrm{~g}=\mathrm{Cin} /$ peso $\times 100$

O peso considerado é o que foi medido no dia do clearance;

3) Fração de excreção de água: $\mathrm{FE} \mathrm{H}_{2} \mathrm{O}=\frac{\mathrm{V}}{\mathrm{C} i n} \times 100(\%)$ onde:

$\checkmark$ é o volume urinário em mililitros/minuto Cin é o clearance de inulina em $\mathrm{mL} / \mathrm{min}$
4) Fração de excreção de sódio e potássio: $\mathrm{FE}=\frac{\mathrm{U} . \mathrm{V} \cdot 100}{\operatorname{Cin} . \mathrm{P}}(\%)$ onde:

U.V é a excreção absoluta do eletrólito

Cin é o clearance de inulina

$\mathrm{P}$ é a concentração plasmática do eletrólito.

5) Cálcio e Magnésio plasmáticos:

Foram medidos pelo método Labtest.

6) Resistência vascular renal:

$\mathrm{RVR}=\mathrm{PA} / \mathrm{FSR}$, onde:

PA: é a pressão arterial do rato medida no dia do clearance;

FSR: é o fluxo sangüíneo renal.

\section{Análise estatística}

Para a análise dos cinco grupos estudados foi utilizado ANOVA com teste de Student - NewmanKeuls para a comparação das colunas entre si. Valores de $p<0,05$ foram considerados significantes.

\section{RESULTADOS}

A depleção de magnésio por 23 dias com queda dos níveis séricos deste cátion não alterou a função renal. De acordo com a Tabela 1 , as medidas funcionais como clearance de inulina, clearance de inulina corrigido pelo peso, volume urinário, dentre outras, foram estatisticamente semelhantes nos grupos controle e hipomagnesêmico. De modo análogo, os valores de hematócrito, PA, FSR e RVR não diferiram significativamente nos dois grupos (Tabela 4).

Como esperado, o grupo hipomagnesêmico apresentou níveis séricos mais baixos de magnésio e do cálcio (Tabela 3).

De acordo com os resultados ilustrados nas Tabelas 1 e 4, observa-se que a hipomagnesemia no contexto de uma isquemia renal levou a uma queda mais acentuada do clearance de inulina, do fluxo sangüíneo renal, bem como aumento da resistência vascular renal. Desta forma, a hipomagnesemia potencializou os efeitos da insuficiência renal aguda (IRA) pós-isquêmica.

Tabela 1- Filtração glomerular (Cin), volume urinário (Vu) e ganho de peso dos animais estudados.

\begin{tabular}{l|l|c|c|c}
\hline & Cin $(\mathbf{m L} / \mathbf{m i n})$ & Cin/100g (mL/min/100g) & Vu (mL/min) & Ganho de peso (g) \\
\hline Controle $(\mathrm{n}=6)$ & $1,92 \pm 0,172$ & $0,77 \pm 0,042$ & $0,0160 \pm 0,0040$ & $98,33 \pm 11,30$ \\
Hipo Mg $(\mathrm{n}=7)$ & $1,96 \pm 0,116$ & $0,83 \pm 0,031$ & $0,0104 \pm 0,0024$ & $70,14 \pm 7,64$ \\
Isquêmico $(\mathrm{n}=8)$ & $0,95 \pm 0,091 \mathrm{a}$ & $0,38 \pm 0,035 \mathrm{a}$ & $0,0191 \pm 0,0041$ & $75,75 \pm 2,42$ \\
Hipo Mg + isq. $(\mathrm{n}=7)$ & $0,48 \pm 0,064 \mathrm{a}$ & $0,22 \pm 0,032 \mathrm{a}$ & $0,0077 \pm 0,0008$ & $56,43 \pm 3,62 \mathrm{~d}$ \\
Suplementado $(\mathrm{n}=6)$ & $1,45 \pm 0,170$ & $0,54 \pm 0,078 \mathrm{c}$ & $0,0105 \pm 0,0012$ & $84,33 \pm 10,29$ \\
\hline
\end{tabular}

$\mathbf{a}, p<0,01$ vs. todos os outros grupos; $\mathbf{b}, p<0,01$ isquêmico vs. suplementado; $\mathbf{c}, p<0,05$ isquêmico vs. suplementado; $\mathbf{d}, p<0,01$ HipoMg+isq. vs. controle. ANOVA. 
Tabela 2- Frações de excreção de água $\left(\mathrm{FeH}_{2} \mathrm{O}\right)$, sódio (FeNa) e potássio (FeK) dos animais estudados.

\begin{tabular}{l|l|l|l}
\hline & Fe $\mathrm{H} O$ & Fe Na & Fe K \\
\hline Controle $(n=6)$ & $0,74 \pm 0,12$ & $0,79 \pm 0,16$ & $13,0 \pm 3,0$ \\
Hipo $\mathrm{Mg}(\mathrm{n}=7)$ & $0,58 \pm 0,12$ & $0,68 \pm 0,18$ & $6,9 \pm 1,13 \mathrm{~d}$ \\
Isquêmico $(\mathrm{n}=8)$ & $1,90 \pm 0,32 \mathrm{a}$ & $1,60 \pm 0,14$ & $23,37 \pm 2,81$ \\
Hipo Mg + isq. $(\mathrm{n}=7)$ & $2,26 \pm 0,54$ & $1,9 \pm 0,72$ & $36,80 \pm 7,74 \mathrm{c}$ \\
Suplementado $(\mathrm{n}=6)$ & $0,77 \pm 0,11 \mathrm{~b}$ & $0,91 \pm 0,13$ & $14,53 \pm 2,52$ \\
\hline
\end{tabular}

a, $\mathrm{p}<0,05$ vs. controle, hipoMg, suplementado; $\mathbf{b}, \mathrm{p}<0,05$ vs. isquêmico, hipoMg+isq.; c, $p<0,05$ vs. todos os outros grupos; $\mathbf{d}, \mathbf{p}<0,05$ vs. controle. ANOVA.
Tabela 3 - Concentrações plasmáticas de magnésio $(\mathrm{Mg})$ e cálcio $(\mathrm{Ca})$ dos animais estudados.

\begin{tabular}{l|l|l}
\hline & $M g(\mathrm{mg} / \mathrm{dL})$ & Ca $(\mathrm{mg} / \mathrm{dL})$ \\
\hline Controle $(\mathrm{n}=6)$ & $1,79 \pm 0,07$ & $9,15 \pm 0,34$ \\
Hipo Mg $(\mathrm{n}=7)$ & $0,81 \pm 0,04$ & $7,27 \pm 0,40$ \\
Isquêmico $(\mathrm{n}=8)$ & $1,51 \pm 0,12$ & $6,2 \pm 0,3 \mathrm{~d}$ \\
Hipo Mg + isq. $(\mathrm{n}=7)$ & $0,37 \pm 0,06 \mathrm{a}$ & $3,7 \pm 0,6 \mathrm{c}$ \\
Suplementado $(\mathrm{n}=6)$ & $2,03 \pm 0,15 \mathrm{~b}$ & $8,48 \pm 0,42$ \\
\hline
\end{tabular}

a, $p<0,05$ vs. controle, isquêmico, suplementado; $\mathbf{b}, p<0,05$ vs. hipoMg; c, $p<0,001$ vs. todos os outros grupos; $d, p<0,01$ vs. controle e suplementado. ANOVA.

Tabela 4 - Hematócrito (Ht), pressão arterial média (PA), fluxo sangüíneo renal (FSR) e resistência vascular renal (RVR) dos animais estudados.

\begin{tabular}{l|l|l|l|c}
\hline & $\mathrm{Ht}(\%)$ & $\mathrm{PA}(\mathrm{mmHg})$ & $\mathrm{FSR}(\mathrm{mL} / \mathrm{min})$ & $\mathrm{RVR}(\mathrm{mmHg} / \mathrm{mL} / \mathrm{min})$ \\
\hline Controle $(\mathrm{n}=6)$ & $45,5 \pm 0,76$ & $119,2 \pm 4,5$ & $7,38 \pm 0,16$ & $16,17 \pm 0,87$ \\
Hipo Mg $(\mathrm{n}=7)$ & $45,3 \pm 3,07$ & $114,3 \pm 3,2$ & $7,30 \pm 0,13$ & $15,86 \pm 0,51$ \\
Isquêmico $(\mathrm{n}=8)$ & $47,0 \pm 1,68$ & $114,4 \pm 2,9$ & $5,9 \pm 0,21 \mathrm{~b}$ & $19,5 \pm 0,73$ \\
Hipo Mg + isq. $(\mathrm{n}=7)$ & $44,0 \pm 2,22$ & $116,4 \pm 2,6$ & $2,7 \pm 0,39 \mathrm{a}$ & $49,71 \pm 7,80 \mathrm{a}$ \\
Suplementado $(\mathrm{n}=6)$ & $48,2 \pm 2,20$ & $110,3 \pm 1,3$ & $5,8 \pm 0,56 \mathrm{~b}$ & $19,97 \pm 1,98$ \\
\hline
\end{tabular}

a, $p<0,001$ vs. todos os outros grupos; $\mathbf{b}, \mathrm{p}<0,01$ vs. controle e hipoMg. ANOVA.

Com relação aos animais submetidos a uma dieta rica em magnésio, estes apresentaram um maior clearance de inulina quando comparados aos ratos submetidos à isquemia e em dieta normal, além de uma menor fração de excreção de água (Tabelas 1 e 2). Estes dados indicam que a suplementação de magnésio protegeu parcialmente os animais da insuficiência renal aguda pósisquêmica. Não se observaram diferenças quanto a hemodinâmica renal entre estes dois grupos de animais (Tabela 4).

O Gráfico 1 mostra os valores de ritmo de filtração glomerular obtidos em todos os grupos.

Em relação às frações de excreção de água e potássio estas diferiram significativamente entre os grupos. A fração de excreção de sódio, porém, não se alterou estatisticamente conforme mostra a Tabela 2.

As concentrações plasmáticas de Magnésio e Cálcio foram significativamente menores nos grupos isquêmicos se comparados aos grupos que não foram submetidos à isquemia. Quando se observa também o grupo suplementado, nota-se um aumento nos níveis destes íons.
Clearance de inulina $/ 100 \mathrm{~g}$ de peso $\mathrm{p}<0,0001$

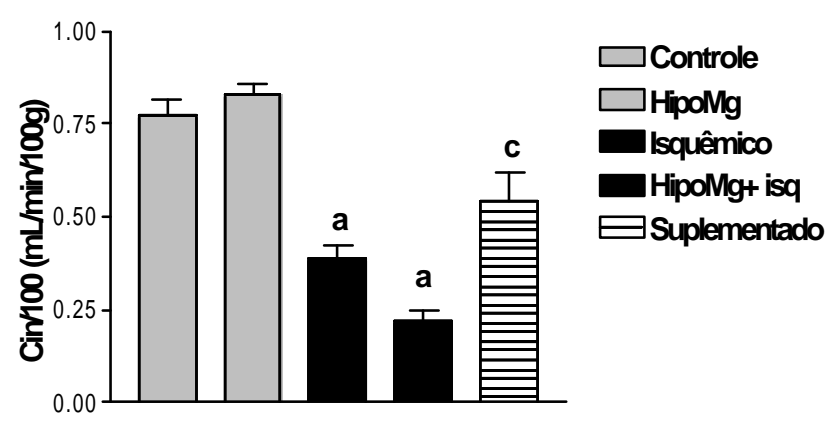

a: $p<0,01$ vs. todos os grupos

c: $\mathrm{p}<0,05$ isquêmico vs. suplementado

Grafico 1 - Valores de ritmo de filtração glomerular obtidos em todos os grupos.

Os Gráficos 2 e 3 mostram as concentrações plasmáticas destes íons vistas em todos os grupos.

A Tabela 4 mostra os valores de hematócrito, pressão arterial, fluxo sangüíneo renal e resistência vascular renal encontrados nos diferentes grupos. 


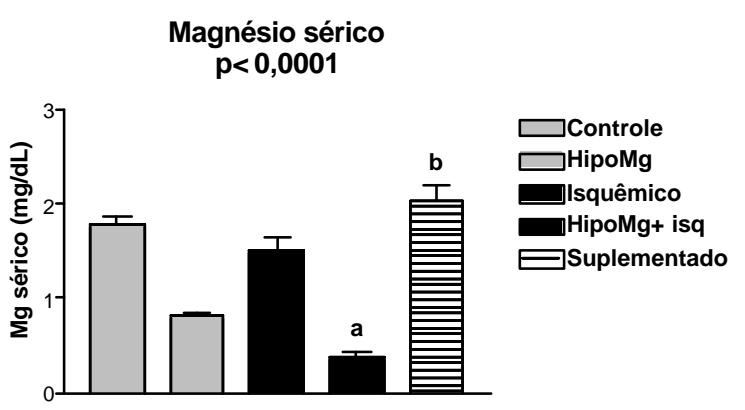

Gráfico 2 - Concentração plasmática de magnésio; a, $p<0,05$ vs controle, isquêmico e suplementado; $b$, $\mathrm{p}<0,05$ vs hipoMg.

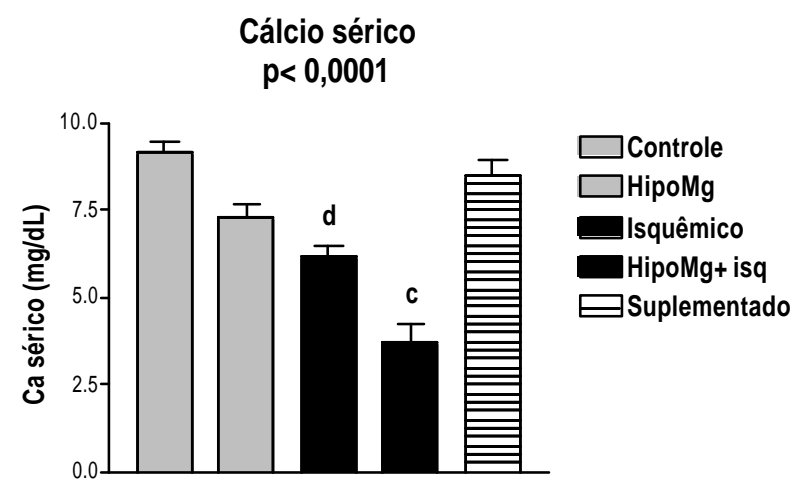

Gráfico 3 - Concentração plasmática de Cálcio c; $p<0,001$ vs. todos os outros grupos $d ; p<0,01$ vs. controle e suplementado.

\section{DISCUSSÃO}

A quantidade de magnésio na dieta é crítica na determinação dos níveis séricos de magnésio. Neste trabalho mostramos que a ausência de sais de magnésio na dieta por 21 dias foi suficiente para que os animais desenvolvessem um grau severo de hipomagnesemia. A desnutrição é muito freqüente em pacientes internados em Unidade de Terapia Intensiva e vários trabalhos observaram deficiência de magnésio muscular e sérico nestes pacientes principalmente nos portadores da síndrome da imunodeficiência adquirida ${ }^{10,18,25}$, indicando que este nosso modelo tem aplicação clínica óbvia.

O clearance de inulina medido 48 horas após isquemia renal nos animais mantidos em dieta normal foi de $0,38 \pm 0,04 \mathrm{ml} / \mathrm{min} / 100 \mathrm{~g}$; cerca da metade dos valores dos animais controles, demonstrando um comprometimento importante da filtração glomerular após este tempo de isquemia e reperfusão renal.

Nos animais com hipomagnesemia foi observado um valor médio de $0,20 \mathrm{ml} / \mathrm{min} / 100 \mathrm{~g}$, evidenciando que o distúrbio metabólico agravou a insuficiência renal.
Dentre os mecanismos possíveis, a vasoconstrição renal mais severa neste grupo de animais que levou à maior queda do fluxo sanguíneo renal nos mesmos ratos parece o mais provável. Em outros territórios como o miocárdio e o cérebro como vimos a hipomagnesemia produz vasoconstrição.

Já foi demonstrado que a hipomagnesemia inibe a liberação de óxido nítrico do endotélio das artérias coronárias ${ }^{24}$. O óxido nítrico como sabemos é um potente vasodilatador endógeno, desta forma, a hipomagnesemia poderia promover vasoconstrição renal via menor produção de óxido nítrico.

O magnésio é um bloqueador dos canais de cálcio $^{2}$. Na deficiência de magnésio ocorre um aumento do cálcio intracelular, o que também pode explicar a maior vasoconstrição e maior lesão celular no grupo de ratos com hipomagnesemia.

Outros mecanismos como aumento da produção de vasoconstritores como a endotelina e de citocinas pró-inflamatórias também já foram descritas neste distúrbio ${ }^{21}$ e provavelmente serão por nós explorados neste modelo com técnicas de imunohistoquímica.

O magnésio está envolvido no balanço iônico intracelular, tendo função importante sobre a atividade da Na-K-ATPase 4 . Na deficiência de magnésio ocorre uma redução dos níveis de ATP intracelular, menor função da Na-K-ATPase com aumento da concentração de sódio intracelular que pode levar à morte da célula. Este é um fator que poderia agravar - grau de necrose na lesão renal após isquemia e reperfusão do rim, como podemos constatar nos nossos experimentos através de maiores frações de excreção de água, sódio e potássio observadas no grupo de animais com hipomagnesemia.

Outro achado interessante neste trabalho foi o menor nível de cálcio plasmático total nos animais com hipomagnesemia. A hipocalcemia é comumente encontrada em associação com a hipomagnesemia. Embora a hipomagnesemia leve estimule a secreção de paratormônio, a hipomagnesemia severa suprime sua secreção assim como a hipermagnesemia, além do que o mecanismo de ação celular do paratormônio necessita de concentrações celulares normais de magnésio pois este cátion é necessário para a atividade da adenil-ciclase que é um transmissor do efeito intracelular do $\mathrm{PTH}^{22}$.

A hipocalcemia é muito freqüente em pacientes graves, principalmente naqueles com síndrome séptica. Existe uma correlação deste distúrbio com a severidade da doença, podendo colaborar com a alta letalidade da insuficiência renal aguda em pacientes desnutridos com hipomagnesemia ${ }^{11}$.

Estes resultados mostram claramente que a hipomagnesemia é um fator agravante da insuficiência 
renal aguda pós-isquêmica e nos motivam a estudar um novo grupo de animais submetidos ao mesmo protocolo de isquemia e reperfusão porém suplementados com cloreto de magnésio a $1 \%$ na água de beber que já utilizamos no Laboratório ${ }^{8}$.

Considerando que a ingestão média de água neste grupo foi de $30 \mathrm{ml}$ por dia, a quantidade ingerida de magnésio pelo rato (35 $\mathrm{mg}$ por dia) foi bem maior do que a existente em uma dieta normal em magnésio que contem $0,22 \mathrm{~g}$ de magnésio por quilo de dieta. Cada rato ingere em média 20 gramas de dieta por dia, portanto cerca de $4 \mathrm{mg} / \mathrm{dia}$.

Nossos resultados mostram claramente que os animais suplementados com magnésio apresentaram uma filtração glomerular significativamente maior que o grupo submetido à isquemia renal mantido em dieta normal.

A suplementação de magnésio tem sido mostrada como benéfica em modelos de insuficiência renal aguda nefrotóxica associados à vasoconstrição como a ciclosporina ${ }^{23}$, e mais recentemente com o indinavir em nosso laboratório ${ }^{8}$.

O fluxo sangüíneo renal não foi diferente quando comparados os animais suplementados ou não com magnésio e submetidos à isquemia. Este fato nos leva a crer que a suplementação de magnésio esteja agindo via aumento do coeficiente de permeabilidade glomerular (Kf). O magnésio pelo seu efeito bloqueador do canal de cálcio diminui a concentração de cálcio intracelular com conseqüente relaxamento das células musculares lisas. O magnésio inibe a contração produzida pela ciclosporina e angiotensina II nas células mesangiais em cultura9.

Este efeito protetor da suplementação de magnésio sobre a insuficiência renal aguda isquêmica será melhor estudado pelo nosso grupo com análise histológica de todos os grupos descritos e estudos de imunohistoquímica com a expressão de moléculas de adesão, PCNA e envolvimento de células como macrófagos e linfócitos.

\section{CONCLUSÃO}

A hipomagnesemia potencializa a insuficiência renal pós-isquêmica por levar a uma queda mais acentuada do clearance de inulina, fluxo sangüíneo renal, bem como aumento da resistência vascular renal. Já a suplementação de magnésio protege parcialmente os animais da insuficiência renal aguda pós isquêmica.

Silva, JC, Seguro AC. Effect of hypomagnesemia and magnesium supplementation on postischemic renal failure. Rev Med (São Paulo) 2002 jan./dez.;81(1/4):1-7.

ABSTRACT: Hypothesis:The aim of this study is to verify the effect of hypomagnesemia and magnesium supplementation on postischemic renal failure. Methods: Five groups of male Wistar rats were studied: control; posthypomagnesemic; post-ischemic; postischemic + hypomagnesemia and post-ischemic + magnesium supplementation. Clearance and hemodynamic measurements were performed.Results: In postischemic rats, hypomagnesemia induces a marked decrease in GFR, RBF and increases the RVR. In rats with Magnesium supplementation increased GFR and decreased $\mathrm{FeH}_{2} \mathrm{O}$ were observed when compared with rats on a normal diet.Conclusion: Hypomagnesemia potentiates postischemic renal failure and magnesium supplementation protects against renal ischemia.

KEYWORDS: Wistar, Rats; Kidney failure, acute/physiopathology; Magnesium deficiency/complication; Dietary supplemments/adverse effects; Ischemy/complications

\section{REFERÊNCIAS}

1. Ariceta G, Rodriguez-Soriano J, Vallo A, Navajas A. Acute and chronic effects of cisplatin therapy on renal magnesium homeostasis. Med Pediatr Oncol 1997;28(1):35-44.

2. Araujo M, Seguro AC. Magnesium supplementation attenuates indinavir nephrotoxicity. J Am Soc Nephrol 2001. [World Congress of Nephrology, 2001. Abstract. A4169].

3. Agus ZS. Hypomagnesemia. J Am Soc Nephrol 1999;10:1616-22.
4. Caddel J, Suskind R, Sillup H, Olsom RE. Parenteral magnesium load evaluation of malnourished Thai childen. J Pediatr 1973;83(1):129-35.

5. Chernow B, Bamberger S, Stoiko M, Vadnais M, Mill S, Hoellerich V, Warshaw AL. Hypomagnesemia in patients in the postoperative intensive care unit. Chest 1989;95(2):391-7.

6. Davis BB, Preuss HG, Murdaugh HV Jr. Hypomagnesemia following the diuresis of postrenal obstruction and renal transplant. Nephron 
1975;14(3-4):275-80.

7. Edmund B Flink. Magnesium deficiency. Etiology and clinical spectrum. Acta Med Scand Suppl 1981;647 (-HD-):125-37.

8. Flatman PW, Lew VL. The magnesium dependence of sodium pump mediated sodium- potassium and sodium- sodium exchange in intact human red cells. J Physiol 1981;315:421-46.

9. Frandey J, Rob PM, Jekelmann W. Theophylline and magnesium inhibit the contraction elicited with ciclosporine and angiotensin II in mesangial cell cultures. Nephron 1991;57(1):94-8.

10. Gupta BK, Glincklich D, Teilis VA. Magnesium repletion therapy improves lipid metabolism in hypomagnesemic transplant recipients: a pilot study. Transplantation 1999;67(11):1485-7.

11. Jeong C, Lee SM. The beneficial effect of ATP- $\mathrm{MgCl}_{2}$ on hepatic ischemia reperfusion-induced mitochondrial dysfunction. Eur J Pharmacol 2000; 403(3):243-50.

12. Johannesson AJ, Raisz LG. Effects of low medium magnesium concentration on bone resorption in response to parathyroid hormone and 1,25 dihydroxy vitamin D in organ culture. Endocrinology 1983; 113(6):2294-8.

13. Kelepouris E, Agus ZS. Hypomagnesemia: renal magnesium handling. Semin Nephrol 1998;18(1):58-73.

14. Liao F, Folsom AR, Brancati FL. Is low magnesium concentration a risk factor for coronary heart disease. The atherosclerosis risk in communities (ARIC) study. Am Heart J 1998;136(3):480-90.

15. Massry SG and Seelig MS. Hypomagnesemia and hypermagnesemia. Clin Nephrol 1977;7(4):14753.

16. Pearson PJ, Evora PR, Seccombe JF, Schaff HV. Hypomagnesemia inhibits nitric oxide release from coronary endothelium. Protective role of magnesium infusion after cardiac operations. Am Thorac Surg
1998;65(4):967-72.

17. Rao TK. Acute renal failure syndromes in human immunodeficiency virus infection. Semin Nephrol 1998;18(4):378-95.

18. Rob PM, Lebeau A, Nobiling R, Schimid H, Bley N, Dick K, et al. Magnesium metabolism: basic aspects and implications of ciclosporine toxicity in rats. Nephron 1996;72(1):59-66.

19. Sameshima H, Ikenoue T. Long- term magnesium sulfate treatment as protection against hypoxicischemic brain injury in seven-day-old-rats. Am J Obstet Gynecol 2001;184(2):185-90.

20. Shechter M, Merz CN, Rude RK, Paul Labrador MJ, Meisel SR, et al. Low intracellular magnesium levels promote platelet-dependent thrombosis in patients with coronary artery disease. Am Heart $\mathrm{J}$ 2000;140(2):212-8.

21. Shechter M, Shavir M, Labrador MJ, Forrester J, Silver $\mathrm{B}$, Bairey Merz CN. Oral magnesium therapy improves endothelial function in patients with coronary artery disease. Circulation 2000;102(19):2353-8.

22. Scheibe F, Haupt H, Vlastos GA. Preventive magnesium supplement reduces ischemia-induced hearing loss and blood viscosity in the guinea pig. Eur Arch Otorhinolaryngol 2000;257(7):355-61.

23. Teregawa $H$, Kato $M$, Yamagata $P$, Matsuura $H$, Kajiyama G. The preventive effect of magnesium on coronary spasm in patients with vasoespastic angina. Chest 2000;118(6):1690-5.

24.Zivin JR, Gooley T, Zager RA, Ryan MJ. Hypocalcemia: a pervasive metabolic abnormality in the critically ill. Am J Kidney Dis 2001;37(4):689-98.

25. Weglicki WB, Phillips TM, Freedman AM, Cassidy MM, Dickens BF. Magnesium deficiency elevates circulating levels of inflammatory cytokines and endothelin. Mol Cell Biochem 1992;110(2):169-73.

26. White RE, Hartzell HC. Effects of intracellular free magnesium on calcium current in isolated myocytes. Science 1988;239(4841 Pt 1):778-80. 